\title{
COME ALONG WITH ME: LINKING LGBTQ YOUTH TO SUPPORTIVE RESOURCES
}

\author{
Jennifer M. Wolowic, Richard Sullivan, Cheryl Ann B. Valdez, \\ Carolyn M. Porta, and Marla E. Eisenberg
}

\begin{abstract}
In this study, we examine how lesbian, gay, bisexual, transgender, and queer (LGBTQ) youth, who tend to experience greater feelings of isolation and discrimination than heterosexual youth, find and become integrated into supportive activities and resources. As part of a larger study on supportive lesbian, gay, bisexual, transgender, and queer youth environments, 66 go-along interviews with LGBTQ youth, from Massachusetts, Minnesota, and British Columbia were conducted. Analysis of these interviews identified important cues that prompt selfagency and integration into supportive environments and affirmative identities. In particular, we argue indirect links or cues such as media and print advertisements increase awareness of supports and resources, while personal links, such as referrals from trusted friends, adults, and regularly attended programs, can help youth form denser networks of support.
\end{abstract}

Keywords: LGBTQ, youth, adolescence, resources, social supports

Jennifer M. Wolowic PhD (the corresponding author) is the Managing Director of the Stigma and Resilience Among Vulnerable Youth Centre, School of Nursing, University of British Columbia, T201-2211 Wesbrook Mall, Vancouver, BC V6T 2B5, Canada. Email: j.wolowic@ubc.ca

Richard Sullivan PhD is a Professor Emeritus, School of Social Work, University of British Columbia, Vancouver, BC V6T 2B5, Canada. Email: Richard.Sullivan@ubc.ca

Cheryl Ann B. Valdez MPH is a graduate of the Graduate School of Public Health, San Diego State University, 5500 Campanile Dr., San Diego, CA 92182, USA. Email: cvaldez@mail.sdsu.edu

Carolyn M. Porta PhD is an Associate Professor in the School of Nursing, University of Minnesota, 308 SE Harvard St, Minneapolis MN 55455, USA. Email: porta@umn.edu

Marla Eisenberg $\mathrm{PhD}$ is an Associate Professor in the Department of Pediatrics, Division of General Pediatrics and Adolescent Health, University of Minnesota, 2450 Riverside Avenue, MN 55454, USA. Email: eisen012@umn.edu 
International Journal of Child, Youth and Family Studies (2018) 9(3): 1-20

This study builds on the literature that asserts affirmative social integration and social support as protective factors in preventing adverse developmental outcomes among lesbian, gay, bisexual, transgender, and queer (LGBTQ) youth (Harper, Brodsky, \& Bruce, 2012; Toro-Alfonso, Varas Díaz, Andújar-Bello, \& Nieves-Rosa, 2006). It is particularly focused on the mechanisms by which such integration is achieved. Predicated on the assumption that, in the course of development toward anticipated social roles, youth will avail themselves of information, people, and settings that can provide affirmation (Blake et al., 2001; Ciro et al., 2005), this study builds on developmental theory (Coleman, 1982), role theory (Bilodeau \& Renn, 2005) and symbolic interactionism (Longmore, 1998).

Developmental theory focuses on adolescence and youth as periods of identity consolidation through rehearsal of various role possibilities in an expanding array of contexts (Collins \& Steinberg, 2007). To that end, the degree of social inclusion a youth perceives or experiences is related to the number of role possibilities open to her or him (Markus \& Nurius, 1986). Similarly, Crone and Dahl (2012) posited that motivations and priorities shift amidst the changing social contexts experienced by adolescents. Martin-Storey, Cheadle, Skalamera, and Crosnoe (2015) explored the social integration of sexual minority youth across different high school contexts and found the presence of positive peer affiliation to be a protective factor, as did Toro-Alfonso et al. (2006).

Young people's social contexts and associated roles provide feedback that may contribute to their developing self-concepts. During development, youth access individuals and programs that support their needs both inside and outside of their schools (Curran \& Wexler, 2017). Self-concept is thus socially constructed from the meanings inferred from both direct and indirect (or symbolic) interaction. The messages about themselves that youth perceive in their social context are therefore consequential. Self-concepts can be influential, even deterministic, in defining a youth's prospects and aspirations (Almeida, Johnson, Corliso, Molnar, \&Azrael, 2009). The availability of positive role models and positive affirming feedback can contribute to youths' sense of their own possibilities.

Research shows that LGBTQ youth often have fewer of these positive social supports and higher rates of risky behaviors, including suicide, than their heterosexual counterparts (Eisenberg \& Resnick, 2006; Marshal et al., 2008; Saewyc, 2011). Other studies have identified that social support programs and psychoeducational programs designed specifically for LGBTQ youth can be important protective factors (Goodenow, Szalacha, \& Westheimer, 2006). Given the risks that these youths may have to contend with, it is important to know more about how they find their way to supportive resources.

In this study we are concerned with social signals or symbols that may communicate the possibility of safety and affirmation with respect to developing LGBTQ identities. We identify 
International Journal of Child, Youth and Family Studies (2018) 9(3): 1-20

some of these communications as direct or indirect links that help youth access new resources that support their identity development.

This approach is also congruent with an ecological perspective and social network theory (Cohen, Underwood, \& Gottlieb, 2000) insofar as it focuses on interconnectivities and social integration of social actors and their access to the developmental resources of their communities. So constructed, our focus is on youths' perceived links to resources facilitative of ongoing development. These links can be constituted in a person (Nesmith, Burton, \& Cosgrove, 1999; Torres, Harper, Sánchez, Fernández, \& The Adolescent Medicine Trials Network for HIV/AIDS Interventions, 2012), but also in any other medium or form of communication that draws the person to a setting that affirms the process of becoming or developing (Craig \& McInroy, 2014; Palmer, 2013). This is an approach to development that recognizes the influences of both personal dispositions and environmental contingencies (Arciero, Gaetano, Maselli, \& Gentili, 2004; Guidano, 1991). In other words, the developing person is both self-generated by their inspirations, identifications, and aspirations, and influenced by the possibilities afforded by their social context.

In this paper, we are concerned with the ways LGBTQ youth learn about and gain access to inclusive activities and supports. We focus on those key prompts that encourage the first attendance and engagement with such activities and supports. Based on our conversations with youth across Minnesota, Massachusetts, and British Columbia, this research explores the relative contribution of direct interpersonal links including individuals and regularly scheduled activities, and more impersonal links such as media outreach and exploration on the internet in leading youth to greater integration with a network of LGBTQ community and broader community supports.

\section{Method}

As part of a larger study exploring social and community elements that affect supportiveness for LGBTQ youth, researchers accompanied 66 participants in an exploration of their environments in order to understand the characteristics of places experienced as safe, unsafe, or welcoming (Eisenberg et al., 2017). Interviews lasted from 35 to 110 minutes and were conducted walking, on transit, and in vehicles in urban, suburban, and rural communities in British Columbia, Minnesota, and Massachusetts. For a fuller discussion of the go-along methods in this

study see Porta et al., 2017. Recruitment occurred in a spectrum of communities in order to identify core common elements of supportive places and spaces as well as common themes for how youth found and accessed resources.

Participants included 24 who identified as male, 21 who identified as female, 11 who identified a binary gender as well as trans, and 10 who identified as having a non-binary gender. In prescreening of participants, we also asked youth to identify their sexual orientations: 24 identified as gay or lesbian; 21 as bisexual; and 19 as queer or other labels including asexual, pansexual, and panromantic; one trans youth identified as "straight", and another defined their orientation as "other". We also intentionally recruited for representation from diverse ethnic 
International Journal of Child, Youth and Family Studies (2018) 9(3): 1-20

backgrounds; 24 youth in our three locations self-identified as having ethnicities other than a White/European background. These included African American, East Asian, Southeast Asian, West Asian, Aboriginal, Hispanic/Latino, Israeli-Canadian, and French Caribbean; some youth identified themselves as having multiple ethnic backgrounds.

Participants were recruited through LGBTQ-serving community organizations, schools, and events. Researchers applied for and received approval from school districts to provide posters and information to school Gender Sexuality Clubs and Gay Straight Alliances (GSAs). Information booths about the study were also set up at LGBTQ conferences. Ethics approval processes and recruitment are described in detail in another publication (Porta et al., 2017). Recruitment through organizations and spaces known to be friendly to LGBTQ youth meant youth who volunteered to participate were often (but not always) already connected to at least one program or support. The overall study sought to document the qualities of these supports and how youth accessed resources.

When scheduling interviews, youths were asked to identify a time they could meet with an interviewer for 45 to 90 minutes and to suggest a location or neighborhood they would want to show the interviewer while talking about safe spaces and supports. Following a go-along methodology (Carpiano, 2009; Kusenbach, 2003; Thompson, Cummins, Brown, \& Kyle, 2013), researchers interviewed the participants as they moved through the youths' chosen spaces. During the go-along interview, the participant gives a tour of the selected area to an interviewer. In this study, participants walked through neighborhoods, schools, and community centres with the interviewers. This created moments during the semi-structured interviews for participants to be prompted by and comment on visual cues in their environment.

The go-along is particularly useful in research with underrepresented or traditionally misrepresented groups because it provides opportunities to ask questions unique to each participants' environment and encounters, in order to see what common elements exist across multiple environments or are unique to a group (Bergeron, Paquette, \& Poullaouec-Gonidec, 2014; Oliver et al., 2011; Sunderland, Bristed, Gudes, Boddy, \& Da Silva , 2012). Using the go-along methodology, this study sought to understand the social ecology of urban, suburban, and rural environments for LGBTQ youth in order to explore what commonalities might define resources and safety for these young people (Garcia, Eisenberg, Frerich, Lechner, \& Lust, 2012).

The open-ended interviews focused on the participants' knowledge of resources in their areas. Interviewers asked questions such as "What clinics, agencies, or resources do you know of that are specifically for LGBTQ youth or who are supportive of LGB youth?", "How did you find out about these places?", and additional questions about access, knowledge, and cues about their environment and LGBTQ inclusivity. The go-along interviews generally paused or concluded in areas where youth felt comfortable sharing their opinions in public or semi-public settings such as a favourite coffee shop or park bench. In these locations, interviewers asked participants to look around and describe what it was about these spaces that made them feel safe in order to gather further details about what the participants deemed as supportive environments and resources. 
International Journal of Child, Youth and Family Studies (2018) 9(3): 1-20

Participants were also asked where they would bring another LGBTQ visitor for various forms of help or simply for pleasure in their community.

Interviews were transcribed by professional transcriptionists who signed confidentiality agreements. The accuracy of the transcripts was checked by the interviewers, who listened to the audio recordings while reading the transcripts. The first round of coding identified visual cues, connections to resources, supportive people, and supportive places. Segments of interviews discussing connections and how youth came to know of or were inspired to access resources were initially coded inductively by the research assistants who conducted the interviews as "bridges". The subset of quotes initially identified as "bridges" were then analyzed further following the second stage of the constant comparison analytic process by the coauthors of the paper (Charmaz, 2000; Glaser, Straus, \& Strutzel, 1968). During this stage, the authors separated and recategorized the kinds of connections identified as "bridges", identifying similarities and differences in, as well as connections between, the various ways youth said they learned of and accessed LGBTQ resources.

Discussion among the coauthors defined some links as more direct than others. The coauthors went back through the sorted quotes again and explored the qualities that made links more or less effective than other kinds of sources mentioned by participants, based on the outcomes of described experiences. Discussion and feedback regarding the coding categories led to renaming "bridges" to "links." With further feedback from peer reviewers for this journal, the coauthors have focused the results on the sources and connections used to reach new supports.

\section{Results}

From the ways participants described learning about and accessing resources, we discerned two different categories that facilitate information sharing and entry into inclusive, affirming resources (Table 1). The first of these we describe as indirect links. These help increase youth awareness of supportive environments and resources, but tend to be circuitous and require a lot of initiative on the part of the youth to begin their involvement. These assist youth in learning about the LGBTQ community and supportive resources. The second category we describe as personal links, which relate to people and events within the youths' circle of relationships and activities. These personal links are predicated on trusted relationships that encourage youth to attend and try new programs and gain stronger social ties within their communities. Participants themselves spoke of the ways people and events or activities and services came across to them or presented themselves so as to invite or discourage their involvement. We have interpreted these instances of impression management as linking mechanisms within a symbolic interactionist framework of social inclusion or social integration in its early stages. 
International Journal of Child, Youth and Family Studies (2018) 9(3): 1-20

Table 1 Links to Supportive Resources for LGBTQ Youth

\begin{tabular}{|c|c|c|}
\hline Connection & Example & Description \\
\hline \multirow[t]{4}{*}{ Indirect links } & $\begin{array}{l}\text { Internet search/ } \\
\text { Social media }\end{array}$ & $\begin{array}{l}\text { Search engines (e.g., Google), online business } \\
\text { directories (e.g., Yelp), social media platforms } \\
\text { (e.g., Tumblr) }\end{array}$ \\
\hline & Print media & Magazines, pamphlets, advertisements, postcards \\
\hline & $\begin{array}{l}\text { Density of networked } \\
\text { resources }\end{array}$ & $\begin{array}{l}\text { Organizations and clinics in close proximity to } \\
\text { each other }\end{array}$ \\
\hline & Events & Gay Pride, Pride parades and related events \\
\hline \multirow[t]{4}{*}{ Personal links } & $\begin{array}{l}\text { Regularly attended } \\
\text { programs }\end{array}$ & School-based Gay-Straight Alliance groups \\
\hline & Supportive adults & $\begin{array}{l}\text { Counselors, educators, clinicians, non- } \\
\text { professional mentors }\end{array}$ \\
\hline & Family & Parents, foster parents, siblings \\
\hline & Friends & $\begin{array}{l}\text { Peers connected through school or other } \\
\text { organizations }\end{array}$ \\
\hline
\end{tabular}

\section{Indirect Links}

Indirect links are constituted by information and environmental variables that youth encounter intentionally and unintentionally as they move through their social, physical, and online environments. These include media such as postings, pamphlets, magazines, and newsletters picked up in coffee shops, bookstores, and health centers that can connect youth to organizations and practitioners. Participants noted online information as an important means of finding out and accessing new activities. Finally, several participants described a multiplicity of services that helped them access new programs. Once they had followed one link and became a part of one program, if other programs were connected to it by notice boards or other means of interagency communication, or even just in the same area geographically, they were made aware of those programs and were more likely to try them. Whether or not they established and sustained interpersonal relationships with people encountered in these settings, they sometimes gained knowledge of and access to other resources.

Internet search/social media: A number of our participants mentioned actively using the internet and social media to connect with similar peers and find resources in their area. Youth noted that these indirect links increased their awareness of activities and supports as well as programs they could choose to attend. For example, when a 17-year-old pansexual gender-fluid participant from Minnesota was asked what they thought was the most common way to hear about supports and resources, they said: 
International Journal of Child, Youth and Family Studies (2018) 9(3): 1-20

Probably just going to LGBT events, or online. People make announcements, or I sign up for things via email and then they'll email me different kinds of supports.... I usually just go on Google and I just [search for] "LGBT resources" or "hangouts" and stuff like that. That's what I do with my friends. We just look up places we could go. We go on Yelp or on the maps or just scrolling through the page and see.

Youth are finding and making judgments about these programs based on comments and the online communities that they discover during their searches. This underscores their personal agency in seeking opportunities for affirmation and inclusion. As with other types of indirect link, youth are seeking out this information themselves; the information is not personally recommended or directed into their hands, but requires effort on their part to connect with these resources.

From the assumed privacy of their personal devices, youth are looking for and discovering accepting social spaces and programs in their communities. A 16-year-old gay participant in British Columbia shared how he found a resource center using the internet:

I use Tumblr a lot and Tumblr's really nice 'cause, like, people can just upload their stuff and, like, I know, like, a lot of social justice Tumblrs and, like, Tumblr's run by, like, queer people. And they, like, have a list of terms or, like, their blog is dedicated to just terms and definitions. And, like, if someone, like, wanted to know something, I'd probably just link it to one of those.

Our participants were proficient computer users who understood how to search key terms and social media sites to find resources in their areas. As an indirect link, the internet helped youth find resources but did not necessarily counter the awkwardness youth could feel when they first accessed resources.

Print media: Magazines, pamphlets, advertisements, postcards, and other forms of print and broadcast media were also noted as ways youth found resources in their areas. Bulletin boards, newsletters, and zines (self-published magazines) were all found in supportive environments and created greater awareness of events and programs of interest to our participants. These were sometimes the first ways they learned of programs or supportive resources for LGBTQ youth.

Youth in each area - Minnesota, Massachusetts, and British Columbia - mentioned such published materials when asked how they found and shared information about resources. For example, an 18-year-old bisexual participant in Minnesota shared that such popular media helped them feel better about themselves and their community:

It makes me feel good knowing that there are places I can go to for help. Not only can I go for help, but also, I can read a magazine. They have a good part for GLBT to read, like maybe a drag show is happening at this place, and I can, like, "Oh, look, there's a drag show. I'm going to go to it", or if there's a GLBT movie that's going on, I'm going to want to go and see that.... It was pretty cool to know that 
International Journal of Child, Youth and Family Studies (2018) 9(3): 1-20

the little pieces of information are in there, so people who are reading The Reader might look at that and go, "Look. It's a GLBT support group that we can go to", and they go to it and get the information they want.

The teenager identified that seeing information about events inspired their attendance and also helped them realize that others might be doing the same.

Posters about events and programs as well as information pamphlets also provided youth with greater awareness of resources in their area. An 18-year-old bisexual male participant from Minnesota shared:

I was thinking I really want to go to [a college], but I'm queer and they might not accept me. I didn't even think to look at a bulletin board and see if they have anything there. You have to keep a peeled eye everywhere because you miss the smallest things and those small things really pay off.... I really wish I'd paid more attention to their bulletin boards, because you can learn a lot from their bulletin boards. I didn't run into any queer youth [at another college], but there were bulletin boards all over with National Coming Out Day, queer trans group, LGBTQ support group, and stuff like that. After seeing that I realized how I missed opportunities.

Visible posters and the kind of events they are advertising provide insight into the level of acceptance youth may encounter in a particular neighborhood, school, or center. Although advertisements provided awareness and information as well as a clue to the neighborhood's acceptance of sexual minorities, they required youths' own initiative to access the programs.

Events: One example of a linking event with salient social potential is the Gay Pride event that is celebrated in many towns and cities across North America and elsewhere. Certainly, attendance at such an event is an instance of direct, personal participation, but it may also be an important, indirect link to community resources insofar as those resources present themselves as participants in the parade and raise awareness of their existence. We were interested to learn how participants assess such events. We asked one 17-year-old pansexual gender-fluid participant from Minnesota what resources they connected with specifically by attending a Pride event. They replied:

Probably just clinics. I can never remember the name of it. It's like [a local health clinic] or something like that. I know within [it] they have a little LGBT shop or whatever you would call it. I think I found that there. Also, just small businesses. I found a lot of different kinds of small businesses from Pride and maybe would check it out later with my friends, that are friendly, or people that are part of the community own it.

Youth in all three sites identified Pride Parades or similar community events as spaces and activities where they learned about health and LGBTQ community support services. Others said 
that Pride events were where they had learned which other schools in their areas had GSAs and support groups, or had learned more about Planned Parenthood.

Events are places where community groups, resources, and supports come together to celebrate, share information, and foster awareness. Participants confirmed that such events are opportunities for youth to gather pamphlets and posters and learn about additional services in their areas. Events can also provide a transition between indirect and personal linkages as youth are often accompanied by friends and families at these events, and in-person interactions are created that lead to further interactions with programs, health care providers, and other members of the LGBTQ community.

However, these interactions required additional follow-up from the youth themselves in order to fully access the resources that are advertised at community events. As such, events are spaces that combine the indirect links through information and advertising with the potential inperson connections that are the foundation of personal involvement.

Density of resources: Given the variety of communities we explored with participants, we believe that the connections among the resources or programs to which youth had access helped them find more resources to incorporate into their social experiences. This suggests that network density or program interconnectedness is helpful to young people seeking to have their various needs met. When one 16-year-old pansexual female participant in British Columbia described to an interviewer how she discovered a youth group, she mentioned her original purpose was to attend the clinic next door:

I went to the clinic next door ... and then I saw the poster and then there was a rainbow painted on the window ... the window looks kind of inviting because of all the different posters saying this is a safe space. And then the clinic's right next to it.

Other participants also described different kinds of youth programs as being located in the same building; attending one would lead to attending others. A further example of network density was provided by a participant who told us about one after school support group at his school splitting into two groups, one that focused on advocating LGBTQ rights while the other continued as a drop-in support group. Many youth attended both. In such cases, physical location and attendance at similar programs created easily accessible links to other programs and supports.

Participants noted that being in a network of resources helped individual resources support one another. For example, a 17-year-old gay teen from Massachusetts noted:

All these organizations have flyers from other organizations, so I feel like all the LGBT organizations here have a close-knit connection with one another. That helps the whole LGBT community in general, because these partnerships show that we're all united or all together. If all the organizations were doing their own thing, it might 
International Journal of Child, Youth and Family Studies (2018) 9(3): 1-20

be much harder for everyone to communicate the different issues that affect our community, because if everyone's not on the same page, then of course not much gets done.

When this participant and others described the resources they used in terms of their proximity and interconnectedness, they associated a higher density of interconnectivity of resources with positive outcomes in their communities. By advertising for one another or being located in similar areas, the network density of these resources helped youth find new programs and supports. For them, these indirect links sometimes also led to interpersonal relationships that we have characterized as personal links to inclusion and affirming social integration.

\section{Personal Links}

Friends, family, and supportive adults were identified among those who initially inspired or encouraged attendance at events and activities that engaged youth in supportive activities. Often these people accompanied the youth or made arrangements that encouraged their participation in LGBTQ events and social circles. In this role, friends, family, and others served as conduits or facilitators in accessing resources and settings where alternative, affirming identities might develop. In these personal links to resources, there is an element of personal agency insofar as there was a trusted person to help youth evaluate the new resources, programs, and people and avoid the awkwardness that often accompanies the first encounter.

Regularly attended programs: Youth who are a part of a GSA or similar program are often directly connected to other programs and resources because of the connections made through these regular meetings and the interpersonal relationships that develop over time. Our participants shared that facilitators or members they would meet in one regularly attended program would often recommend other programs, events, or resources. For example, an 18-year-old bisexual participant from Minnesota shared, "I think it's good that people are saying, 'Hey, there's this one place you should go to with me sometime.' " These sorts of frequent encounters built relationships between youth that helped the participants find out about, get referred to, and feel comfortable attending the programs. In this way, such relationships can be a personal link to other resources and introduce youth to supportive adults in their community. In Minnesota, for example, a 17-year-old pansexual gender-fluid participant shared:

In my old GSA class, people would go to it, and then they'd come back and talk about it with the class. They said they met a lot of nice people, and even just going to the coffee shop, they tell you other events you could go to, so just going one place gives you more places to go, in a way. 
International Journal of Child, Youth and Family Studies (2018) 9(3): 1-20

In British Columbia, a 15-year-old queer female described how the GSA clubs in the school district were connected:

There's a district GSA and we meet every month. We met yesterday for January with our teacher, who's the district GSA leader thing. And we all try to go for those meetings, and we all see each other once a month, and we hang out on the side.

Through meeting people at clubs and regularly attended meetings, youth share information. An 18-year-old bisexual participant from Minnesota described:

Going to GSA and hearing, "I hear there's this one place you guys should check out", or going to a counselor and asking if there's a place or any support group you could go to and they just hand it out, like, "There's this one place you should check out if you have the time."

These illustrations show how LGBTQ youth seek and share new activities and spaces and then share their findings with others. The relationships that formed with peers and adult facilitators in the process served as personal links to supportive social integration.

Supportive adults: Participants described supportive adults interacting with them in both informal and professional roles. The latter included school counselors, coaches, and teachers who helped motivate participants to join new activities and provided information about resources. These adults asked important questions and encouraged youth to find supports if they felt the youth might benefit from them.

A 16-year-old queer trans male in Massachusetts shared how several different professionals in his life were supportive of him. When asked how he found out about an LGBTQ youth group he said, "My doctor. When I first came out to my doctor, my doctor told me about an LGBTQ health center, and from there, I got connected with a therapist, and the therapist recommended me to the youth group." These professionals served as personal links to social integration insofar as they directly linked this youth to services and supports.

Youth also described non-professional mentors or trusted adults who connected them to professional services. For example, in Minnesota, an 18-year-old pansexual male participant shared his story:

When I moved out, I went and stayed with my ... she was my girlfriend at the time. We're not dating anymore, but her mom was really supportive and stuff. She asked me if I wanted to go to counseling... She actually did a bunch of research at one point, or went on some website and printed out a packet of paper that had a bunch of different resources, like a whole list of resources that I'm like overwhelmed with.

In this example, a well-meaning adult in a non-professional role intentionally assisted this young person by doing the work necessary to find suitable therapists and to ensure that the participant 
was informed of their availability. Participants shared that adults, in both professional and nonprofessional relationships with youth, often provided the first link to resources and offered important continuing support that helped them attend new programs, find therapists, and meet other youth. To the extent that these people facilitated social integration, we believe them to be links in the chain of social interactions that help LGBTQ youth achieve affirming social inclusion.

Family: Families were also helpful. Different participants in British Columbia, Minnesota, and Massachusetts told us of parents, step-parents, foster parents, and grandparents helping to identify supportive resources and transport participants to those resources. For example, one 16year-old trans participant from Minnesota told us of the important role their mother played when we asked how they got connected to programs in their area:

[My mom] was trying to find every little resource or anything. Oh, at [local area]

High School there is a girl named [name]. She is the best person you could talk to.

Best person. I don't like the school, but I love her.

One 18-year-old rainbow-sexual participant in British Columbia shared that his foster parents took the role of mediators and helped him find a clinic: "When I was in my foster home I told them I wanted to get tested, and they took me to a clinic to get a piece of paper to go to the place that I have to go to get tested."

Siblings also played important roles in sharing information and facilitating connections. In one instance, a sibling provided the location of a café she knew to be queer-friendly. In another, a sibling acted as an ally for the study participant by warning that their parents were concerned about some of the sites the youth had visited on his computer and being supportive of his attendance at an LGBTQ youth rally. In yet another example, an older sibling was also a sexual minority person and served as a guide to available resources and information about their suitability for youth.

Parents and siblings have unique opportunities to create supportive homes, but our participants also described how family intentionally connected them to various supports outside the home, including clinical resources, supportive churches, sports organizations, and informal social opportunities, and facilitated their participation. The choices these family members made in facilitating connections to LGBTQ community resources further illuminate the dynamics by which social inclusion is achieved.

Friends: Many of the youth we spoke with described their friends as offering the strongest kind of personal support. Friends provide the emotional support and prompting that helps connect youth to resources and regularly occurring events and programs. Among our participants, access to supportive groups like GSA clubs in high schools, and to counseling for LGBTQ youth, was often facilitated by friends with prior knowledge of the group or resource. In short, friends take their friends along to these events so that, as with any other social induction process, connection begets other connections in the process of social integration. 
International Journal of Child, Youth and Family Studies (2018) 9(3): 1-20

In Minnesota, a 15-year-old bisexual teen described how he entered his school's GSA. When asked how he heard about the club he replied:

My friend. I met her in the library at school and we were just talking, and she was like, "You should come to [GSA group] with me. It's every Monday." I was like, “Okay”, because I was thinking about starting my own LGBT group. I didn't know that there was already one.

We heard many similar stories from our study participants. Another 18-year-old bisexual participant from Minnesota described going to a weekly recreational event at a local recreation center because of the encouragement of their friends:

I started going to my GSA when my friends were like, "Hey, I know you're trying to hide it, but you really suck at it. We all know you're bi or gay or something. We know you're something." They invited me to their national day out thing, where they paraded around the lunchroom for like three lunch periods with posters. "I'm not gay, but my boyfriend is." "Gay teachers rock." We just shouted, "We're here, we're queer, don't be afraid to come and find us." And then from there I found out through different friends who went to [a drop in] at an alternate school ... I found out about [it] from there.

Professional staff associated with a youth's school might also provide personal connections to various resources, but the availability and effect of such a person is often mediated by a peer. Peer familiarity with helpful people, organizations, and activities was noted as an important factor not only in club attendance but also for drop-in and support groups outside of school. An 18-year-old lesbian participant from Massachusetts described her experience of going to a LGBTQ drop-in space with a friend:

During that time, I was confused about gender identity and stuff, so I went in there with this other trans guy I was hanging out with. He pulled me along there. He was like, "You're struggling with stuff. Come with me." I was like, "no." I walked in there; they made me write down my name on a piece of paper and this counselor pulled me aside into a room and made me talk with her, which is nice but really intimidating.

Peers helped participants understand why clubs, supports, and other resources could be helpful. For example, a 17-year-old pansexual trans male participant from British Columbia told us:

I'm assisting a friend as well with trans things. And, well, he hasn't really looked anything up himself 'cause he's a little nervous about it. So I've been looking up a bunch of groups and different doctors and everything like that for him as well. 
International Journal of Child, Youth and Family Studies (2018) 9(3): 1-20

Friends not only referred participants to resources, but undertook the important acts of conducting research and attending these activities with their friends.

A 16-year-old pansexual female youth in British Columbia also helped explain why friends were so helpful for participants:

Often times you look it up and you're not really sure even though it says that, like, it's that kind of place, it might not be. Like, you find that a lot with, like, people who are transgender and they go to a doctor and it turns out their doctor is really transphobic and, like, doesn't want them to transition. Even though, like, they advertise that that's what they could help with. They usually, like, start trying to, like, cure them mentally. So it's hard; you can't really trust regular resources to find that kind of place.

Peers played an important role in encouraging participants to join programs, attend clinics, and meet with supportive adults.

Peers review resources for one another and create pathways through their supportive words and actions. Trust, as a feature of peer relationships, enables a form of mediated referral. Peer support of the resources thus constitutes a validating reference.

\section{Discussion}

Our findings illustrate the efforts of LGBTQ youth to explore the social ecologies of their lives and settings. This is a developmentally adaptive process oriented to the identification of sites wherein the exploration of prospective roles and identities is supported and affirmed (Arciero et al., 2004; Craig \& McInroy, 2014). In this sense, the developing person is cast as both a selfgenerating agent and the subject of external influences and opportunities. Either directly or indirectly, people, events, and public communications via media as varied as bulletin boards and the internet can serve to connect LGBTQ young people to sites of safety and support. Many participants in our study accessed several different resources that together created a network of programs and resources they regularly attended. Inevitably, direct engagement with supportive resources is most effective, but this does not negate the importance of easily accessible information when it comes to facilitating engagement.

Clear, complete, easily accessible information can help LGBTQ youth take the first steps in becoming aware of and judging the relevance or suitability of supports in their geographical area. In a small study, Craig and McInroy (2014) identified electronic media as often being chosen by LGBTQ youth for the first points of contact in accessing resources, exploring identity, and making initial on-line appraisals and forays into communities of peers; off-line contact may follow. Social media provided a safe, anonymous place to learn about others' coming out experiences with their families and also a place to rehearse new identities and roles. 
Participants in a study by Greene, Fisher, Kuper, Andrews, and Mustanski (2015) described how best to reach out to LGBTQ youth. The 72 ethnoculturally diverse participants in the study consistently recommended the use of positive, affirming symbols and messages to attract the interest of LGBTQ youth. This study focused on prospective dyadic sexual health interventions for young same-sex couples with attention to their relationship concerns and their preferences for the content and form of intervention. For those still questioning or not "out" in most of their social contexts, accessible but discreet messages could serve as links to sexual health information and social supports that could be assessed first from some social distance. The ways in which information is presented also shape young people's choices about where to locate themselves socially with respect to education and other settings of preparation for adult roles.

In our study, participants gave clear evidence of how they used the information they had gleaned about the safety and prospects for affirmation of different settings to plan for future involvement. LGBTQ youth are actively and frequently looking for symbols of safety and acceptance in spaces and among people (Wolowic et al., 2017). Effective outreach requires communication in language and other symbols conducive to youth engagement. Symbols and images can attract youths' attention and help youth assess the potential of indirect and personal links they encounter.

Personal relationships with trusted individuals were often sources of referrals for youth when they entered new programs or services. The trusted assessment of peers and adults moderates their involvement in newly discovered resources, events, and supports. Symbolic interaction theory, with its focus on the importance of role models and reference groups as mediating factors, sheds light on the ways in which minority stress can be mediated by identification with affirming reference group members. In this sense, an alternative perspective can correct the harmful effects of internalized homophobia learned in majority contexts (Cox, Vanden Berghe, Dewaele, \& Vincke, 2010; Meyer, 2003).

Throughout our study, participants described their families and parents as mediators or pathways between their offspring's experience and the larger social world, as we have seen in a previous analysis of data from this study (Mehus, Watson, Eisenberg, Corliss, \& Porta, 2017). Many participants reported that their parents sought resources to affirm their offspring's changing sense of self and buffer against adverse influences. Even where family response was tentative, guarded, or contrary, it formed part of the context in which participants explored their social world. The variety of family responses reported by participants reflects the diversity of a sample that ranged from first-generation immigrant families with cultural origins not inclusive of gender role variants to liberal families that had already embraced some measure of gender role variability. In the latter instance, families sometimes served as personal guides and allies in accessing supportive services. Where families were less supportive, friends took on an even more important role.

Friends were important because they not only verbally encouraged attendance, but made the important offer to go with our participants to make introductions and test out new resources 
International Journal of Child, Youth and Family Studies (2018) 9(3): 1-20

with them. First-person referrals from other youth who attended programs or were patients or clients themselves were important pathways that recruited new youth to these resources. This made trust, or at least positive expectation, possible as a first step on the pathway to engagement and utilization.

Our findings affirm the salience of support and access for LGBTQ youth in achieving social integration, albeit to varying degrees, during the process of affirming social identities and finding resources. The first step in that process involves the assessment of whom to trust in seeking support and resources. As in Sherriff, Hamilton, Wigmore, and Giambrone's (2011) study of the factors that influence LGBTQ youths' decisions about whom to trust regarding their sexuality or their search for information about resources, participants described a range of characteristics that drew them to the persons they invited to guide them, with perceived experience, competence, and sensitivity figuring significantly in deciding whom to trust. This highlights the salience of selfagency in the selection of the developmental and interpersonal pathways by which social integration unfolds.

Through the variety of communities we explored with participants, the idea of resource density emerged wherein individual resources or programs helped youth find new or more resources to incorporate into their social experiences. When youth described a density of resources and interconnected indirect and personal pathways in their communities, this was often associated with effective programming and positive outcomes in their communities. Our findings show that LGBTQ youths' self-agency can be facilitated by closer interconnectivity of resources and greater density of the different kinds of links that youth encounter.

\section{Conclusion}

The young people in this study were proactively engaged in the exploration of their social ecologies. This is an expected developmental task that forms part of the process of role rehearsal and eventual identity consolidation. While ease of access to supportive sites might not be achieved for all LGBTQ youth, let alone proactive network density, resources within a geographical area are encouraged to share information and promote related supports and services in order to maximize their effectiveness within a network of support. Professionals, parents, and others associated with LGBTQ youth can serve directly or indirectly as pathways to safety. For many youth, the role that friends played in introducing them to groups or activities was critical; therefore, organizations may wish to promote a "bring a friend day" or similarly encourage these bridging initiatives. For the professionals working within these networks, knowing that our actions and communications are being assessed by youth can serve as a reminder that our communications can serve as signals to hope, despair, indifference, or any number of other possibilities. Those who are assessed to be useful will serve as pathways to affirmative developmental outcomes. 
International Journal of Child, Youth and Family Studies (2018) 9(3): 1-20

\section{References}

Almeida, J., Johnson, R. M., Corliso, H. L., Molnar, B. E., \&Azrael, D. (2009). Emotional distress and LGBT youth: The influence of perceived discrimination based on sexual orientation. Journal of Youth \& Adolescence, 38(7), 1001-1014. doi:10.1007/s10964-0099397-9

Arciero, G., Gaetano, P., Maselli, P., \& Gentili, N. (2004) Identity, personality and emotional regulation. In A. Freeman, M. J. Mahoney, P. Devito, \& D. Martin (Eds.), Cognition and psychotherapy (2nd ed., pp. 7-18). New York, NY: Springer.

Bergeron, J., Paquette, S., \& Poullaouec-Gonidec, P. (2014). Uncovering landscape values and micro-geographies of meanings with the go-along method. Landscape and Urban Planning, 122, 108-121. doi:10.1016/j.landurbplan.2013.11.009

Bilodeau, B. L., \& Renn, K. A. (2005). Analysis of LGBT identity development models and implications for practice. New Directions for Student Services. Special issue: Gender identity and sexual orientation: New directions for student services, 111, 25-40. doi:10.1002/ss.171

Blake, S. M., Ledsky, R., Lehman, T., Goodenow, C., Sawyer, R., \& Hack, T. (2001). Preventing sexual risk behaviors among gay, lesbian and bisexual adolescents: The benefits of gaysensitive HIV instruction in schools. American Journal of Public Health, 91, 940-946. doi:10.2105/AJPH.91.6.940

Carpiano, R. M. (2009). Come take a walk with me: The "Go-Along" interview as a novel method for studying the implications of place for health and well-being. Health \& Place, 15(1), 263-272. doi:10.1016/j.healthplace.2008.05.003

Charmaz, K. (2000). Experiencing chronic illness. In G. L. Albrecht, R. Fitzpatrick, \& S. C. Scrimshaw (Eds.), Handbook of social studies in health and medicine (pp. 277-292). doi: $10.4135 / 9781848608412 . n 18$

Ciro, D., Surko, M., Phandarkar, K., Helfgott, N., Peake, K., \& Epstein, I. (2005). Lesbian, gay, bisexual, sexual-orientation questioning adolescents seeking mental health services: Risk factors, worries, and a desire to talk about them. Social Work in Mental Health, 3, 213-234. doi:10.1300/J200v03n03_01

Cohen, S., Underwood, L. G., \& Gottlieb, B. H. (Eds.). (2000). Social support measurement and intervention: A guide for health and social scientists. Oxford, UK: Oxford University Press.

Coleman, E. (1982) Developmental stages of the coming out process. Journal of Homosexuality, 7(2), 31-43. doi:10.1300/J082v07n02_06 
International Journal of Child, Youth and Family Studies (2018) 9(3): 1-20

Collins, W. A., \& Steinberg, L. (2007). Adolescent development in interpersonal context. Handbook of Child Psychology, 111, 16. doi:10.1002/9780470147658.chpsy0316

Cox, N., Vanden Berghe, W., Dewaele, A., \& Vincke, J. (2010). Acculturation strategies and mental health in gay, lesbian, and bisexual youth. Journal of Youth and Adolescence, 39(10), 1199-1210. doi:10.1007/s10964-009-9435-7

Craig, S. L., \& McInroy, L. (2014). You can form a part of yourself online: The influence of new media on identity development and coming out for LGBTQ youth. Journal of Gay \& Lesbian Mental Health, 18(1), 95-109. doi:10.1080/19359705.2013.777007

Crone, E. A., \& Dahl, R. E. (2012). Understanding adolescence as a period of social-affective engagement and goal flexibility. Nature Reviews Neuroscience, 13(9), 636-650. doi:10.1038/nrn3313

Curran, T., \& Wexler, L. (2017). School-based positive youth development: A systematic review of the literature. Journal of School Health, 87(1), 71-80. doi:10.1111/josh.12467

Eisenberg, M. E., Mehus, C. J., Saewyc, E. M., Corliss, H. L., Gower, A. L., Sullivan, R., \& Porta, C. M. (2017). Helping young people stay afloat: A qualitative study of community resources and supports for LGBTQ adolescents in the U.S. and Canada [Online]. Journal of Homosexuality, August, 1-21. doi:10.1080/00918369.2017.1364944

Eisenberg, M. E., \& Resnick, M. D. (2006). Suicidality among gay, lesbian and bisexual youth: The role of protective factors. Journal of Adolescent Health, 39(5), 662-668. doi:10.1016/j.jadohealth.2006.04.024

Garcia, C. M., Eisenberg, M. E., Frerich, E. A., Lechner, K. E., \& Lust, K. (2012). Conducting go-along interviews to understand context and promote health. Qualitative Health Research, 22(10), 1395-1403. doi:10.1177/1049732312452936

Glaser, B. G., Strauss, A. L., \& Strutzel, E. (1968). The discovery of grounded theory: Strategies for qualitative research. London, UK: Aldine Transaction.

Goodenow, C., Szalacha, L., \& Westheimer, K. (2006). School support groups, other school factors, and the safety of sexual minority adolescents. Psychology in the Schools, 43(5),573-589. doi:10.1002/pits.20173

Greene, G. J., Fisher, K. A., Kuper, L., Andrews, R., \& Mustanski, B. (2015). "Is this normal? Is this not normal? There is no set example": Sexual health intervention preferences of LGBT youth in romantic relationships. Sexuality Research and Social Policy, 12(1), 1-14. doi:10.1007/s13178-014-0169-2

Guidano, V. F. (1991). The self in process: Toward a post-rationalist cognitive therapy. New York NY: Guilford Press. 
International Journal of Child, Youth and Family Studies (2018) 9(3): 1-20

Harper, G. W., Brodsky, A., \& Bruce, D. (2012) What's good about being gay? Perspectives from youth. Journal of LGBT Youth, 9(1), 22-41. doi:10.1080/19361653.2012.628230

Kusenbach, M. (2003). Street phenomenology: The go-along as ethnographic research tool. Ethnography, 4(3), 455-485. doi:10.1177/146613810343007

Longmore, M. A. (1998) Symbolic interactionism and the study of sexuality. Journal of Sex Research, 35(1), 44-57. doi:10.1080/00224499809551916

Markus, H, \& Nurius, P. (1986). Possible selves. American Psychologist, 41(9), 954-969. doi:10.1037/0003-066X.41.9.954

Marshal, M. P., Friedman, M. S., Stall, R., King, K. M., Miles J., Gold, M. A., ... Morse, J. Q. (2008). Sexual orientation and adolescent substance use: A meta-analyses and methodological review. Addiction, 103(4), 546-556. doi:10.1111/j.1360-0443.2008.02149.x

Martin-Storey, A., Cheadle, J. E., Skalamera, J., \& Crosnoe, R. (2015). Exploring the social integration of sexual minority youth across high school contexts. Child Development, 86(3), 965-975. doi:10.1111/cdev.12352

Mehus, C. J., Watson, R. J., Eisenberg, M. E., Corliss, H. L., \& Porta, C. M. (2017). Living as an LGBTQ adolescent and a parent's child: Overlapping or separate experiences. Journal of Family Nursing, 23(2), 175-200. doi:10.1177/1074840717696924

Meyer, I. H. (2003) Prejudice, social stress, ad mental health in lesbian, gay, and bisexual populations: Conceptual issues and research evidence. Psychological Bulletin, 129(5), 674697. doi:10.1037/0033-2909.129.5.674

Nesmith, A. A., Burton, D. L., \& Cosgrove, T. J. (1999). Gay, lesbian, and bisexual youth and young adults: Social support in their own words. Journal of homosexuality, 37(1), 95-108. doi:10.1300/J082v37n01_07

Oliver, M., Witten, K., Kearns, R. A., Mavoa, S., Badland, H. M., Carroll, P., ... Ergler, C. (2011). Kids in the city study: Research design and methodology. BMC Public Health, 11(1), 587. doi:10.1186/1471-2458-11-587

Palmer, N. A. (2013). LGBT youth online and in person: Identity development, social support, and extracurricular and civic participation in a positive youth development framework [Doctoral dissertation]. Vanderbilt University, Nashville, TN.

Porta, C. M., Corliss, H., Wolowic, J. M., Johnson, A. Z., Fogel, K. F., Gower, A. L., ... Eisenberg, M.E. (2017). Go-along interviewing with LGBTQ youth in Canada and the United States. Journal of LGBT Youth, 14(1):1-15. doi:10.1080/19361653.2016.1256245 
International Journal of Child, Youth and Family Studies (2018) 9(3): 1-20

Saewyc, E. M. (2011). Research on adolescent sexual orientation: Development, health disparities, stigma and resilience. Journal of Research on Adolescence, 21(1), 256-272. doi:10.1111/j.1532-7795.2010.00727.x

Sherriff, N. S., Hamilton, W. E., Wigmore, S., \& Giambrone, B. L. B. (2011). "What do you say to them?" Investigating and supporting the needs of lesbian, gay, bisexual, trans, and questioning (LGBTQ) young people. Journal of Community Psychology, 39(8), 939-955. doi:10.1002/jcop.20479

Sunderland, N., Bristed, H., Gudes, O., Boddy, J., \& Da Silva, M. (2012). What does it feel like to live here? Exploring sensory ethnography as a collaborative methodology for investigating social determinants of health in place. Health \& Place, 18(5), 1056-1067. doi:10.1016/j.healthplace.2012.05.007

Thompson, C., Cummins, S., Brown, T., \& Kyle, R. (2013). Understanding interactions with the food environment: An exploration of supermarket food shopping routines in deprived neighbourhoods. Health \& Place, 19, 116-123. doi:10.1016/j.healthplace.2012.10.003

Toro-Alfonso, J., Varas Díaz, N., Andújar-Bello, I., \& Nieves-Rosa, L. E. (2006). Strengths and vulnerabilities of a sample of gay and bisexual male adolescents in Puerto Rico. Interamerican Journal of Psychology, 40(1), 55-64.

Torres, R. S., Harper, G. W., Sánchez, B., Fernández, M. I., \& The Adolescent Medicine Trials Network for HIV/AIDS Interventions. (2012). Examining natural mentoring relationships (NMRs) among self-identified gay, bisexual, and questioning (GBQ) male youth. Children and Youth Services Review, 34(1), 8-14. doi:10.1016/j.childyouth.2010.12.018

Wolowic, J. M., Heston, L. V., Saewyc, E. M., Porta, C., \& Eisenberg, M. E. (2017). Chasing the rainbow: Lesbian, gay, bisexual, transgender, and queer youth and pride semiotics. Culture, Sexuality and Health, 19(5), 557-571. doi:10.1080/13691058.2016.1251613 